\title{
Sistem Pakar Diagnosa Pulmonary TB Menggunakan Metode Fuzzy Logic
}

\author{
Nita Novianti ${ }^{1}$, Denny Pribadi ${ }^{2}$, Rizal Amegia Saputra ${ }^{3}$ \\ ${ }^{1}$ STMIK Nusa Mandiri Sukabumi \\ e-mail: novianti_1812@yahoo.com \\ 2 STMIK Nusa Mandiri Sukabumi \\ e-mail: denny.dpi@nusamandiri.ac.id \\ ${ }^{3}$ AMIK BSI Sukabumi \\ e-mail: rizal.rga@bsi.ac.id
}

\begin{abstract}
Abstrak
Tuberkulosis paru merupakan salah satu penyakit menular kronis. Di Indonesia penyakit ini termasuk satu prioritas nasional untuk program pengendalian penyakit karena berdampak luas terhadap kualitas hidup dan ekonomi, serta sering mengakibatkan kematian. Untuk itu, dalam penelitian ini akan dilakukan analisa terhadap penyakit tb paru menggunakan logika fuzzy (fuzzy logic). Dalam penelitian ini informasi tentang tb paru didapat dari para pakar dengan melakukan wawancara dengan pakar. Berdasarkan uraian diatas maka dibuat sebuah aplikasi sistem pakar untuk mendiagnosa tb paru menggunakan fuzzy logic. Aplikasi sistem pakar berbasis web untuk mendiagnosa penyakit tb paru merupakan kebutuhan dari asisten dokter dan masyarakat umum. Oleh karena itu agar mendapatkan nilai informasi yang tepat dan cepat aplikasi sistem pakar ini akan dalam bentuk website. Dari 7 gejala yang ditimbulkan oleh penyakit to paru ini dalam perhitungan fuzzy logic di dapat sebanyak 128 rule dan untuk perhitungan persentase keakuratannya sendiri sebesar $70,33 \%$. Pembuatan aplikasi ini akan sangat membantu dalam melakukan diagnosa terhadap penderita tb paru.
\end{abstract}

Kata Kunci: Sistem Pakar, Fuzzy Logic, Penyakit TB Paru, Aplikasi Web

\begin{abstract}
Pulmonary Tuberculosis is one of an infectious disease chronic. In indonesia this disease including one national priorities to control program disease due affect widely to the quality of life and economic, and often resulting in death. For it, in this research will analysis to a disease pulmonary TB use fuzzy logic. Based on the description above will be made an application expert system to diagnose pulmonary TB use fuzzy logic. Expert system application with web based for disease diagnose is the needs of an assistant docter and the general public. Therefore To make gain the value of the most appropriate information and rapid application expert system this is going to in the form of websites. Of 7 symptoms that were brought about by disease pulmonary tuberculosis this in the calculation of fuzzy logic in be some 128 rule and for percentage accurate of $70,33 \%$. The making of the application it would be very helpful in doing the diagnosis against patients pulmonary tuberculosis.
\end{abstract}

\section{Keywords : Expert System, Fuzzy Logic, Pulmonary Tb, Web Applications}

\section{Pendahuluan}

Penyakit Tuberculosis (TB) adalah penyakit menular yang disebabkan oleh bakteri yang disebut Mycobacterium Tuberculosis (Orhan, Temurtas, \& Tanrıkulu, 2010). Pada umumnya penyakit TB menyerang paru sehingga disebut dengan TB paru atau Pulmonary TB. Kuman TB berbentuk batang dan memiliki sifat khusus, yaitu tahan terhadap asam pada pewarnaan, sehingga sering disebut juga sebagai Basil Tahan Asam (BTA). (Arumsari \& Bujojo, 2010).

Tuberkulosis paru

(TB.Paru) merupakan salah satu penyakit menular kronis yang menjadi isu global yang menjadi sasaran dalam MDGs (Millennium Development Goals) dan juga tercantum didalam Standar Pelayanan Minimal kesehatan. $\mathrm{Di}$ Indonesia penyakit ini 
termasuk satu prioritas nasional untuk program pengendalian penyakit karena berdampak luas terhadap kualitas hidup dan ekonomi, serta sering mengakibatkan kematian (Laksono, Astuti, Waty, \& Atto'illah , 2012), melakukan diagnosis secara dini itu sangat penting, agar dapat mengurangi penularan TB kepada masyarakat luas (Saputra, 2014)

Logika fuzzy merupakan suatu nilai dapat bernilai true dan false secara bersamaan, tapi tergantung pada bobot keanggotaan yang dimilikinya, Logika fuzzy digunakan untuk menterjemahkan suatu nilai yang diekspresikan dalam bahasa (linguistic) (Huzumah \& Arifn, 2018).

Logika fuzzy umumnya diterapkan pada masalah-masalah yang mengandung unsur ketidakpastian (uncertainty), ketidaktepatan (imprecise) dan noisy ( Wulandari \& Prasetyo, 2018)

Kelebihan dari logika fuzzy adalah kemampuan dalam proses penalaran secara bahasa (Linguistic Reasoning). Sehingga dalam perancangannya tidak memerlukan persamaan matematika dari objek yang akan dikendalikan (Nasution, 2012).

Ada beberapa ahli yang telah melakukan penelitian yang berkaitan dengan penelitian ini, diantaranya:

1. Penelitian oleh Istri Sulistyowati tahun 2011 yang berjudul Implementasi Sistem Pakar Berbasis Web Untuk Mendiagnosa Penyakit Dalam Pada Manusia. Menjelaskan bahwa pembuatan aplikasi sistem pakar berbasis web untuk mendiagnosa penyakit dalam ini merupakan kebutuhan dari seorang asisten dokter dan masyarakat umum. Dimana dalam aplikasi tersebut sistem pakar akan memberikan suatu pernyataan dan informasi yang didapat dari pakar, sistem akan mengambil kesimpulan dengan cepat dan tepat. Dengan aplikasi tersebut kemungkinan terjadi kesalahan diagnosa bisa dihilangkan dan proses penanganan terhadap pasien bisa dilakukan dengan cepat.

2. Penelitian oleh Helfi Nasution tahun 2012 yang berjudul Implementasi Logika Fuzzy pada Sistem Kecerdasan buatan. Menjelaskan bahwa logika fuzzy (fuzzy Logic) dapat membantu dalam membuat perangkat lunak kecerdasan buatan, dimana dalam pembuatan perangkat lunak kecerdasan buatan memiliki daerah yang tidak memiliki aturan yang jelas atau nilai-nilai absolut. Dalam setiap kasus dimana jawabannya akan "kadang-kadang" atau "mungkin" logika fuzzy sangat membantu.

3. Penelitian oleh Agung Dwi Laksono dkk tahun 2012 yang berjudul Kajian standar pelayanan minimal penyakit tuberculosis terkait indikator millennium development goals. Menjelaskan bahwa Tuberkulosis paru merupakan salah satu penyakit menular kronis yang menjadi isu global yang menjadi sasaran di dalam MDGs(Millennium Development Goals) dan juga tercantum di dalam SPM (Standar Pelayanan Minimal) kesehatan. Di Indonesia penyakit ini termasuk salah satu prioritas nasional untuk program pengendalian penyakit karena berdampak luas terhadap kualitas hidup dan ekonomi, serta sering mengakibatkan kematian.

\section{Metode Penelitian \\ Kerangka Pemikiran}

Kerangka pemikiran dalam perancangan ini dimulai dengan identifikasi masalah dan perumusan masalah yang dapat dibuat sistem pakar, kemudian menentukan basis pengetahuan dan menerapkan logika fuzzy yang akan digunakan sehingga dapat di implementasikan pada aplikasi sistem pakar yang dibuat.

\section{Metode Pengumpulan Data}

Pengumpulan data pada penelitian ini menggunakan studi pustaka dengan mengambil referensi dari jurnal nasional maupun internasional, dari buku-buku yang berkaitan dengan pembahasan, serta metode observasi dan wawancara

\section{Sistem Pakar}

Sistem pakar merupakan cabang dari kecerdasan buatan dan juga merupakan bidang ilmu yang muncul seiring perkembangan ilmu komputer saat ini(Perwira \& Aziz, 2013). Sistem ini adalah sistem komputer yang bisa meniru kemampuan seorang pakar, sistem ini bekerja untuk mengadopsi pengetahuan manusia kekomputer yang menggabungkan dasar pengetahuan (knowladge base) dengan sistem inferensi untuk 
menggantikan fungsi seorang pakar dalam menyelesaikan suatu masalah (Fanny , Hasibuan, \& Buulolo, 2017).

\section{Fuzzy Logic}

Logika fuzzy adalah peningkatan dari logika boolean yang mengenalkan konsep kebenaran sebagian. Dimana logika klasik menyatakan bahwa segala hal dapat diekspresikan dalam sebuah binary ( 0 atau 1 , hitam atau putih, ya atau tidak), logika fuzzy menggantikan kebenaran boolean dengan tingkat kebenaran (Nasution, 2012).

\section{Basis Pengetahuan}

Basis pengetahuan terbentuk dari fakta-fakta dan aturan yang berupa informasi tentang cara bagaimana menimbulkan fakta baru dari fakta yang sudah diketahui. Pengetahuan ini merupakan representasi pengetahuan dari seorang pakar yang diperlukan untuk memahami, memformulasikan dan memecahkan masalah.

Tabel 1. Tabel Pakar

\begin{tabular}{|c|c|c|c|c|c|c|c|}
\hline \multirow{2}{*}{ Rule } & \multicolumn{6}{|c|}{ Gejala-gejala TB Paru } \\
& G0 & G0 & G0 & G0 & G0 & G0 & G0 \\
& 01 & 02 & 03 & 04 & 05 & 06 & 07 \\
\hline H001 & $\sqrt{ }$ & $\sqrt{ }$ & $\sqrt{ }$ & $\sqrt{ }$ & $\sqrt{ }$ & $\sqrt{ }$ & $\sqrt{ }$ \\
\hline $\mathrm{H} 002$ & & & & & & & \\
\hline
\end{tabular}

Keterangan :

Baris pertama pada tabel pakar menerangkan gejala yang ditimbukan oleh penyakit Tb Paru (Pulmonary TB), diantaranya:

G001 : Batuk berdahak disertai darah $>2$ minggu

G002 : Demam

G003 : Keringat dingin pada waktu malam hari

G004 : Berat badan turun tanpa alasan yang jelas

G005 : Dada terasa sakit

G006 : Nafas Sesak

G007 : Nafsu makan berkurang

Kolom pertama pada tabel pakar menerangkan rule hasi dari para pakar mengenai penyakit TB Paru (Pulmonary TB), diantaranya:

$\mathrm{H} 001$ : Ya

H002 : Tidak

\section{Logika Sistem Pakar}

Berikut uraian rule-rule dari sistem pakar diagnosa TB Paru menggunakan metode fuzzy logic:

\section{Rule Pertama}

IF (Batuk IS Kronis) AND (Demam IS Tinggi) AND (Keringat IS tidak) AND (Nafas IS Sesak) AND (Berat Badan IS Turun) AND (Nafsu Makan IS kurang) AND (Dada Sakit IS Ya) THEN (Hasil Positif TB Paru)

\section{Rule Kedua}

IF (Batuk IS Kronis) AND (Demam IS Tinggi) AND (Keringat IS Normal) AND (Nafas IS Sesak) AND (Berat Badan IS Turun) AND (Nafsu Makan IS kurang) AND (Dada Sakit IS Ya) THEN (Hasil Positif TB Paru)

\section{Rule Ketiga}

IF (Batuk IS Normal) AND (Demam IS Normal) AND (Keringat IS Normal) AND (Nafas IS Normal) AND (Berat Badan IS Normal) AND (Nafsu Makan IS Normal) AND (Dada Sakit IS Tidak) THEN (Hasil Negatif TB Paru)

\section{Rule Keempat}

IF (Batuk IS Kronis) AND (Demam IS Tinggi) AND (Keringat IS Tidak) AND (Nafas IS Normal) AND (Berat Badan IS Normal) AND (Nafsu Makan IS Normal) AND (Dada Sakit IS Tidak) THEN (Hasil Negatif TB Paru)

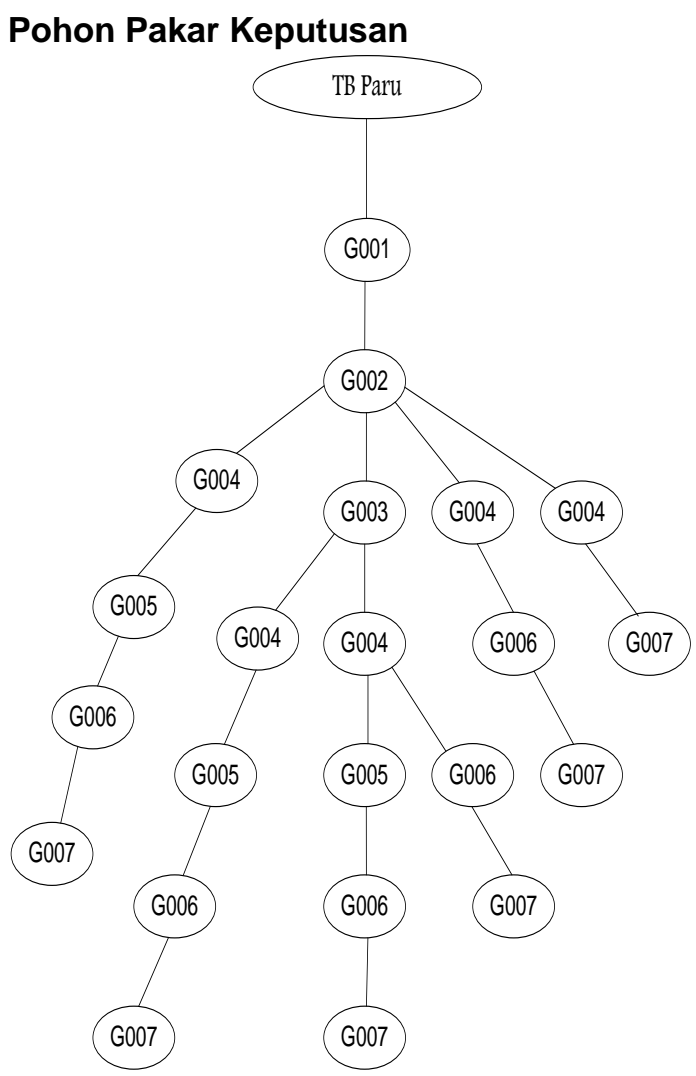

Gambar 1. Pohon Pakar (Decision Tree) 
3. Hasil dan Pembahasan

\subsection{Hasil Perhitungan Fuzzy}

Tabel 2. Tahapan Pengaburan (Fuzzyfication)

\begin{tabular}{|l|l|}
\multicolumn{3}{|c|}{ (Fuzzyfication) } \\
\hline Normal & Variable Batuk \\
\hline Kronis & $0-10$ \\
\hline \multicolumn{3}{|c|}{ Variable Demam } \\
\hline Normal & $0-36$ \\
\hline Tinggi & $30-39$ \\
\hline \multicolumn{3}{|c|}{ Variable Nafas } \\
\hline Normal & $0-20$ \\
\hline Sesak & $15-30$ \\
\hline \multicolumn{3}{|c|}{ Variable Nafsu Makan } \\
\hline Normal & $0-5$ \\
\hline Kurang & $3-10$ \\
\hline \multicolumn{3}{|c|}{ Variable Berat Badan } \\
\hline Normal & $0-5$ \\
\hline Turun & $3-10$ \\
\hline \multicolumn{3}{|c|}{ Variable Keringat } \\
\hline Normal & $0-5$ \\
\hline Tidak & $3-10$ \\
\hline \multicolumn{2}{|c|}{ Variable Dada Sakit } \\
\hline Tidak & $0-5$ \\
\hline Ya & $3-10$ \\
\hline \multicolumn{2}{|c|}{} \\
\hline
\end{tabular}

Untuk semantik atau derajat keanggotaan dihitung menggunakan rumus $(-(x-d) /(d$ $-c), c<x \leq d)$ dan $((x-a) /(b-a), a<x<$ b)

a. Fungsi derajat keanggotaan untuk variable batuk

Derajat keanggotaan untuk normal dihitung menggunakan rumus $-(x-d) /$ $(d-c), c<x \leq d$, dimana $x=7, c=5$ dan $d=10$. Sehingga derajat keanggotaan normal $=-(7-10) /(10-5)=3 / 5$. Sedangkan untuk Derajat keanggotaan kronis dihitung menggunakan rumus $(x$ - a) / $(b-a), a<x \leq b$, dimana $x=7, a=5$ dan $b=10$. Sehingga derajat keanggotaan normal $=(7-5) /(10-5)=$ $2 / 5$.

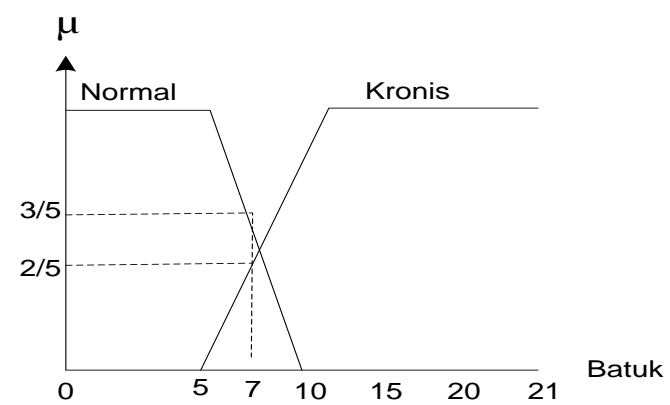

Gambar 2. Fungsi Keanggotaan Trapesium Untuk Batuk b. Fungsi derajat keanggotaan untuk variable demam

Derajat keanggotaan untuk normal dihitung menggunakan rumus $-(x-d) /$ $(d-c), c<x \leq d$, dimana $x=35, c=30$ dan $d=36$. Sehingga derajat keanggotaan normal $=-(35-36) /(36-30)$ $=1 / 6$. Sedangkan untuk Derajat keanggotaan tinggi dihitung menggunakan rumus $(x-a) /(b-a)$, $a$ $<x \leq b$, dimana $x=35, a=30$ dan $b=36$. Sehingga derajat keanggotaan tinggi $=$ $(35-30) /(36-30)=5 / 6$.

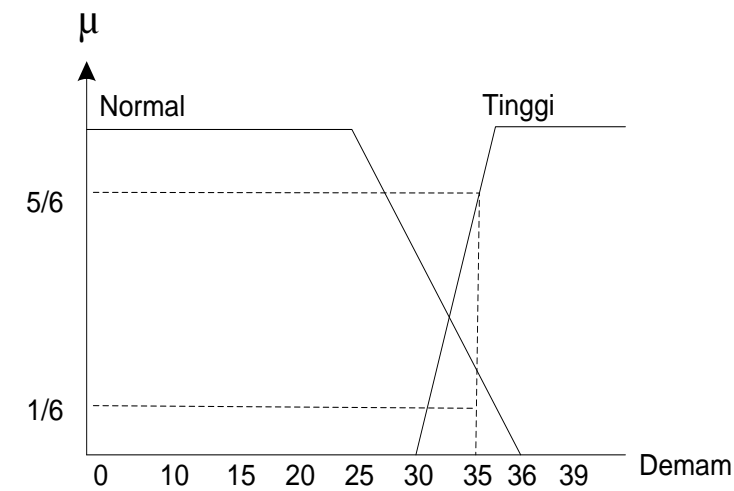

Gambar 3. Fungsi Keanggotaan

Trapesium Untuk Demam

c. Fungsi derajat keanggotaan untuk variable nafas

Derajat keanggotaan untuk normal dihitung menggunakan rumus $-(x-d) /$ $(d-c), c<x \leq d$, dimana $x=18, c=15$ dan $d=20$. Sehingga derajat keanggotaan normal $=-(18-20) /(20-15)$ $=2 / 5$. Sedangkan untuk Derajat keanggotaan kronis dihitung menggunakan rumus $(x-a) /(b-a)$, $a$ $<x \leq b$, dimana $x=18, a=15$ dan $b=20$. Sehingga derajat keanggotaan sesak= $(18-15) /(20-15)=3 / 5$.

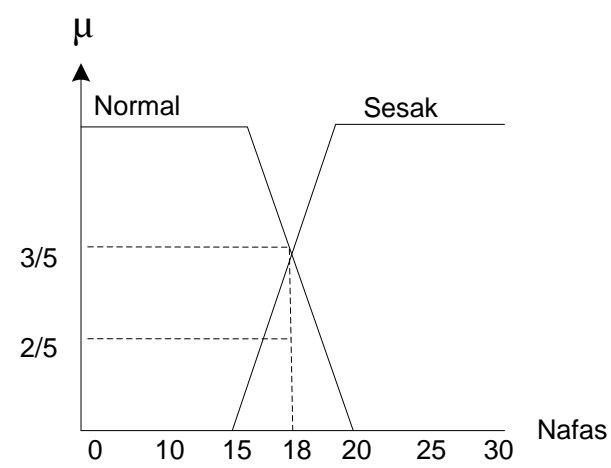

Gambar 4. Fungsi Keanggotaan Trapesium Untuk Nafas 
d. Fungsi derajat keanggotaan untuk variable nafsu makan

Derajat keanggotaan untuk normal dihitung menggunakan rumus $-(x-d) /$ $(d-c), c<x \leq d$, dimana $x=4, c=3$ dan $d=5$. Sehingga derajat keanggotaan normal $=-(4-5) /(5-3)=1 / 2$. Sedangkan untuk Derajat keanggotaan kurang dihitung menggunakan rumus $(x-a) /$ $(b-a), a<x \leq b$, dimana $x=4, a=3$ dan $b=5$. Sehingga derajat keanggotaan kurang $=(4-3) /(5-3)=2 / 2$.

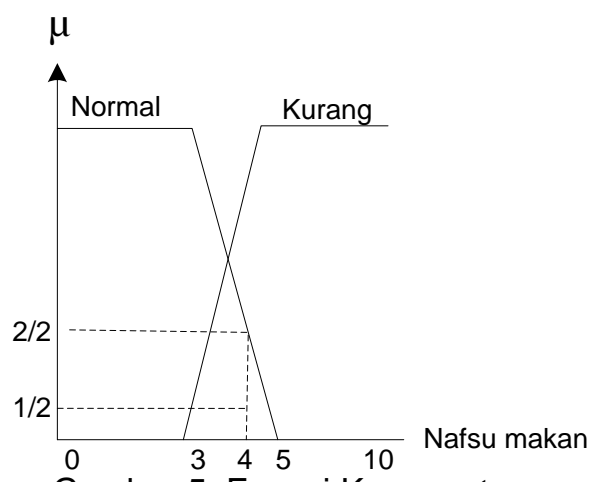

Gambar 5. Fungsi Keanggotaan

Trapesium Untuk Nafsu makan

e. Fungsi derajat keanggotaan untuk variable berat badan

Derajat keanggotaan untuk normal dihitung menggunakan rumus $-(x-d) /$ $(d-c), c<x \leq d$, dimana $x=4, c=3$ dan $d=5$. Sehingga derajat keanggotaan normal $=-(4-5) /(5-3)=1 / 2$. Sedangkan untuk Derajat keanggotaan turun dihitung menggunakan rumus $(x-a) /$ $(b-a), a<x \leq b$, dimana $x=4, a=3$ dan $b=5$. Sehingga derajat keanggotaan turun $=(4-3) /(5-3)=2 / 2$.

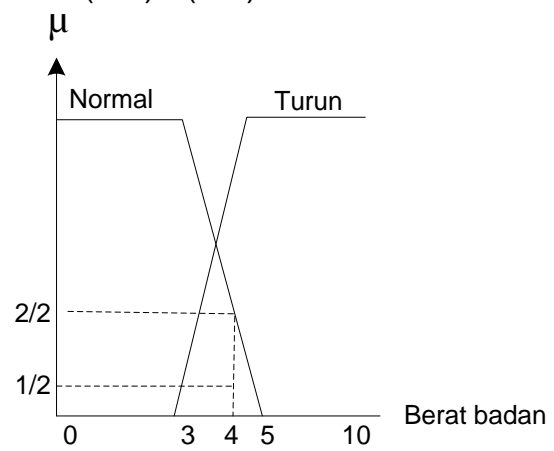

Gambar 6. Fungsi Keanggotaan

Trapesium Untuk Berat Badan

f. Fungsi derajat keanggotaan untuk variable keringat

Derajat keanggotaan untuk normal dihitung menggunakan rumus $-(x-d) /$ $(d-c), c<x \leq d$, dimana $x=4, c=3$ dan $d=5$. Sehingga derajat keanggotaan normal $=-(4-5) /(5-3)=1 / 2$. Sedangkan untuk Derajat keanggotaan tidak dihitung menggunakan rumus $(x-a) /$ $(b-a), a<x \leq b$, dimana $x=4, a=3$ dan $b=5$. Sehingga derajat keanggotaan tidak $=(4-3) /(5-3)=2 / 2$.

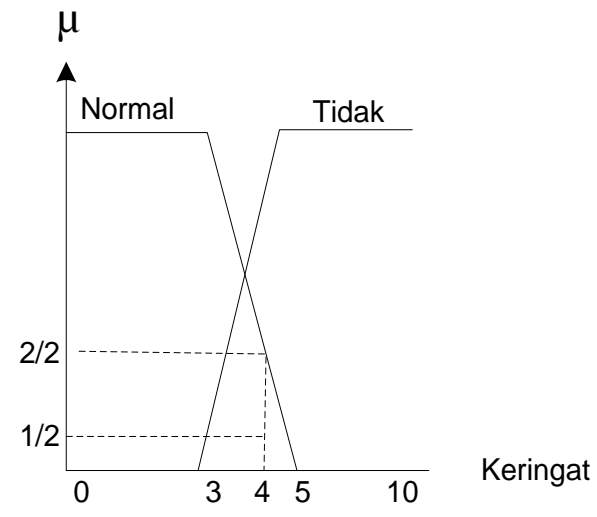

Gambar 7. Fungsi Keanggotaan

Trapesium Untuk Keringat

g. Fungsi derajat keanggotaan untuk variable dada sakit

Derajat keanggotaan untuk tidak dihitung menggunakan rumus $-(x-d) /$ $(d-c), c<x \leq d$, dimana $x=4, c=3$ dan $d=5$. Sehingga derajat keanggotaan tidak $=-(4-5) /(5-3)=1 / 2$. Sedangkan untuk Derajat keanggotaan ya dihitung menggunakan rumus $(x-a) /(b-a)$, $a$ $<x \leq b$, dimana $x=4, a=3$ dan $b=5$. Sehingga derajat keanggotaan ya $=(4-$ $3) /(5-3)=2 / 2$.

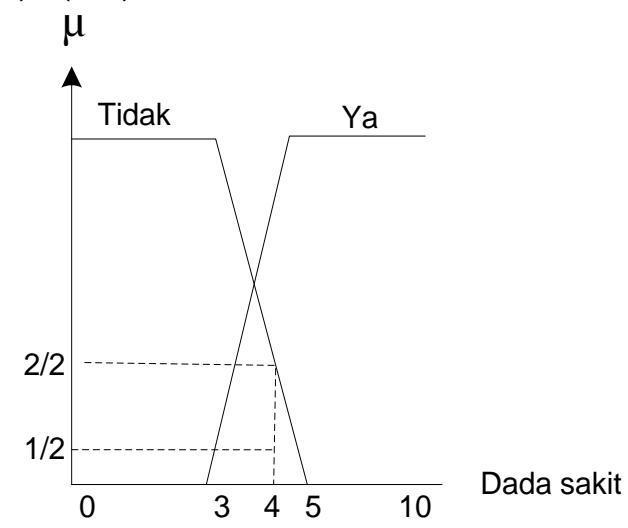

Gambar 8. Fungsi Keanggotaan Trapesium Untuk Dada Sakit

\section{Proses Inference Menggunakan Mamdani}

Membuat empat aturan yang diaplikasikan sebagai proses perhitungan defuzzyfication untuk mendapatkan persentase dari penerapan metode ini untuk pendiagnosaan TB Paru. 
1. IF (Batuk IS Kronis) 2/5 AND (Demam IS Tinggi) 5/6 AND (Keringat IS tidak) 2/2 AND (Nafas IS Sesak) 5/5 AND (Berat Badan IS Turun) 2/2 AND (Nafsu Makan IS kurang) 2/2 AND (Dada Sakit IS Ya) 2/2 THEN (Hasil is Positif TB Paru) 2/2

2. IF (Batuk IS Kronis) 2/5 AND (Demam IS Tinggi) 5/6 AND (Keringat IS Normal) 1/2 AND (Nafas IS Sesak) 2/2 AND (Berat Badan IS Turun) 2/2 AND (Nafsu Makan IS kurang) AND (Dada Sakit IS Tidak) 1/2 THEN (Hasil is Positif TB Paru) $1 / 2$

3. IF (Batuk IS Normal) $3 / 5$ AND (Demam IS Normal) $1 / 6$ AND (Keringat IS Normal) 1/2 AND (Nafas IS Normal) 5/5 AND (Berat Badan IS Normal) 1/2 AND (Nafsu Makan IS Normal) 1/2 AND (Dada Sakit IS Tidak) 1/2 THEN (Hasil is Negatif TB Paru) $1 / 2$

4. IF (Batuk IS Kronis) 2/5 AND (Demam IS Tinggi) 5/6 AND (Keringat IS Normal) 1/2 AND (Nafas IS Normal) 5/5 AND (Berat Badan IS Normal) 1/2 AND (Nafsu Makan IS Normal) 1/2 AND (Dada Sakit IS Tidak) 1/2 THEN (Hasil is Negatif TB Paru) $1 / 2$

Digunakan aturan Disjunction (v) dengan memilih derajat keanggotaan maximum dari nilai-nilai linguistic yang dihubungkan oleh v. Dari 'Hasil is Positif $(2 / 2)$ v Hasil is Positif (1/2)' dihasilkan 'Hasil is Positif $(2 / 2)$ '. Sedangkan dari 'Hasil is Negatif (1/2) $\vee$ Hasil is Negatif (1/2)' dihasilkan 'Hasil is Negatif 1/2'. Dengan demikian diperoleh dua pernyataan: Hasil is Positif (2/2) dan Hasil is Negatif (1/2). Proses inference Model Mamdani menggunakan proses clipping menghasilkan dua area abu-abu seperti berikut:

\section{Proses Defuzzyfication}

$y^{*}=\frac{(30+33+40+43+45) 1 / 2+(68+78+88+98+100) 2 / 2}{\frac{1}{2}+\frac{1}{2}+\frac{1}{2}+\frac{1}{2}+\frac{1}{2}+\frac{2}{2}+\frac{2}{2}+\frac{2}{2}+\frac{2}{2}+\frac{2}{2}}$ $y^{*}=\frac{527.5}{7.5}=70,33 \%$

jadi, dengan menggunakan model mamdani, untuk diagnosa tb paru menghasilkan tingkat persentase sebesar $70,33 \%$
3.2. Entity Relationship Diagram

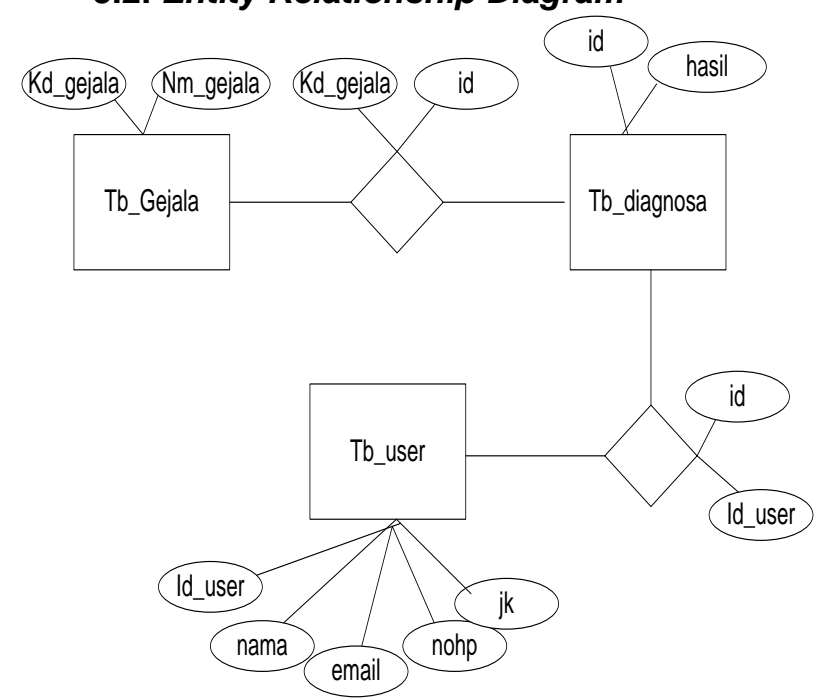

Gambar 9. Entity Relationship Diagram

\subsection{Unified Modeling Language (UML)}

UML yang digunakan dalam membangun aplikasi ini menggunakan usecase diagram dan activity diagram. Yaitu sebagai berikut:

\section{a. Usecase Diagram Halaman User}

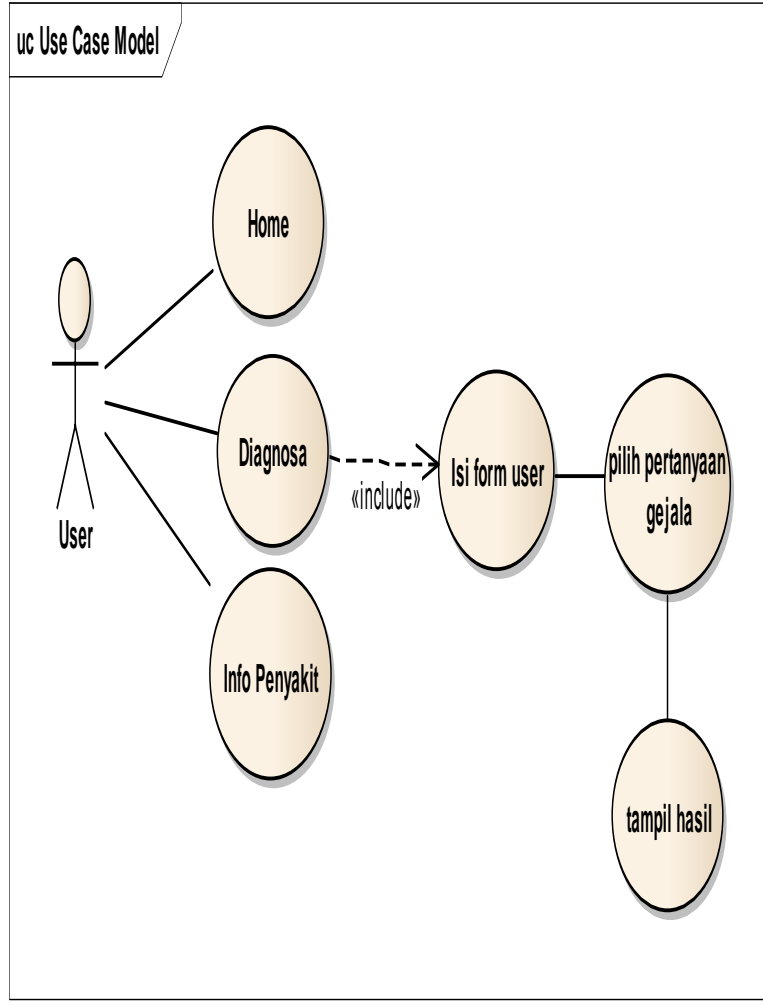

Gambar 10. Usecase Diagram User 
b. Activity Halaman User

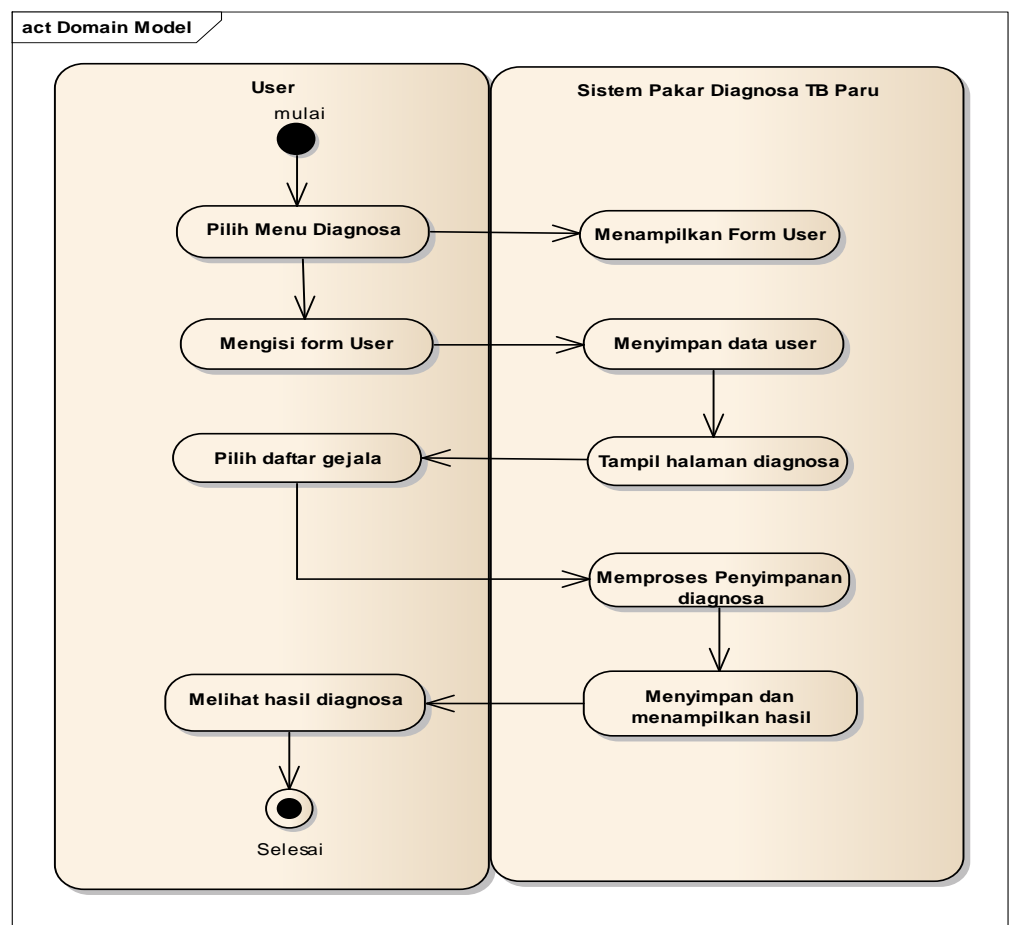

Gambar 11. Activity Diagram User

\subsection{Implementasi}

a. Halaman Admin

1) Form login

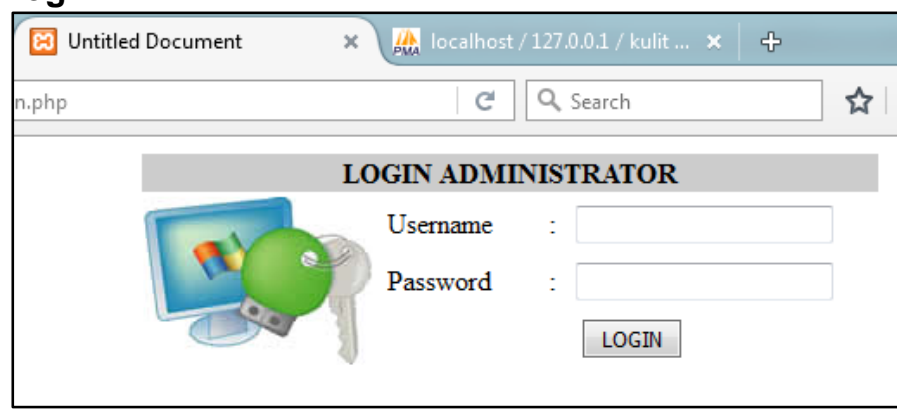

Gambar 12. Form Login Admin

2) Fom Kelola Gejala

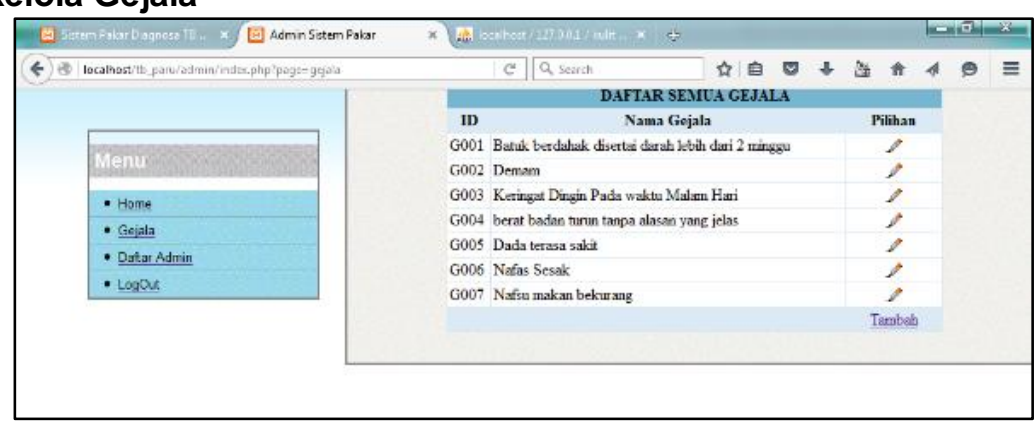

Gambar 13. Halaman Kelola Gejala 


\section{3) Form Kelola admin}

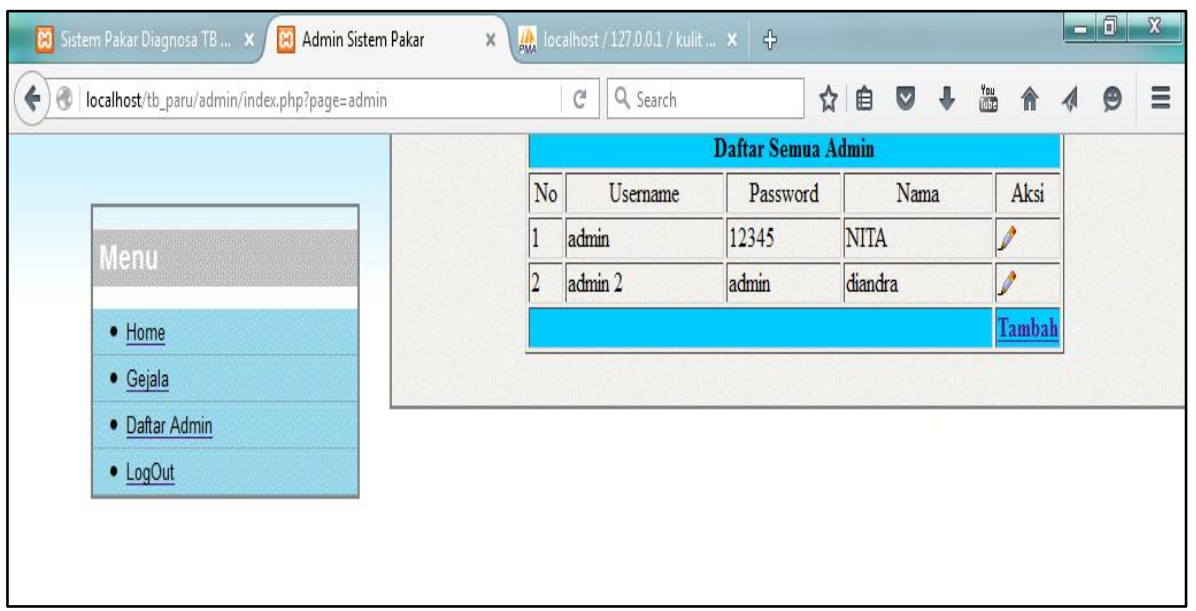

Gambar 14. Halaman Kelola Admin

\section{b. Halaman User}

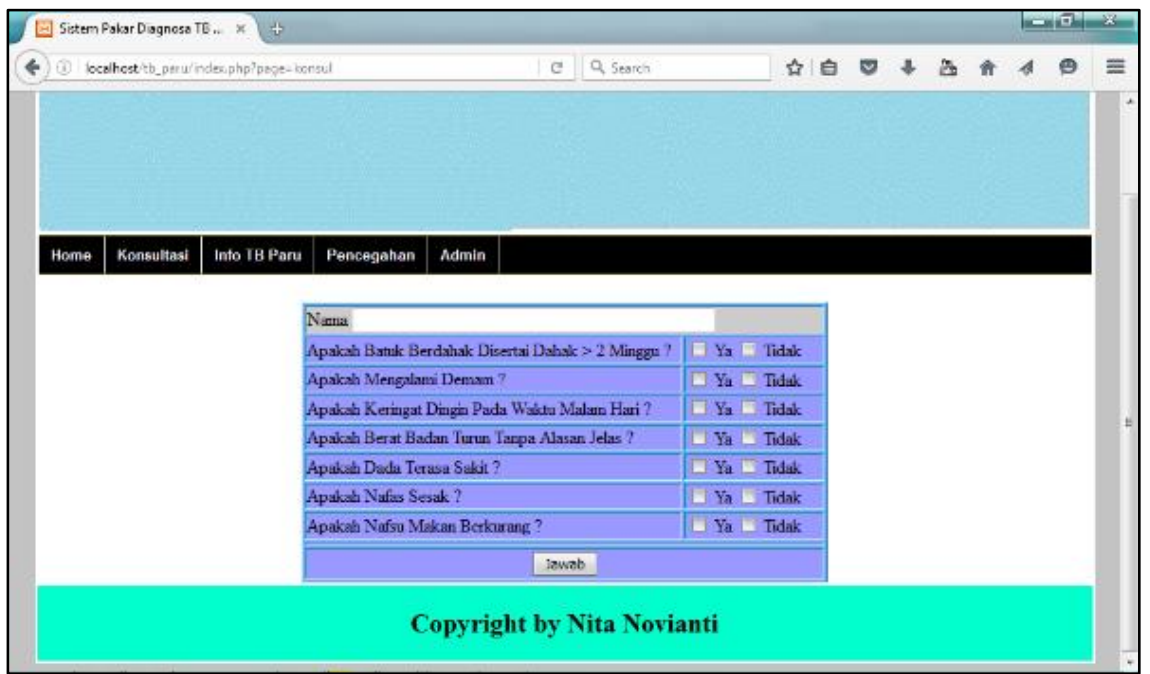

Gambar 15. Halaman Diagnosa

\section{Kesimpulan}

Dari pembuatan sistem pakar untuk diagnosa Pulmonari TB dengan menggunakan metode fuzzy logic mamdani mengahasilkan tingkat keakuratan diagnose sebesar $70,33 \%$. Aplikasi sistem pakar ini dibuat agar penggunanya dapat mendapatkan informasi mengenai penyakit tb paru, tanpa harus melakukan konsultasi dengan para tenaga medis, Aplikasi sistem pakar ini di buat dalam bentuk website, sehingga memudahkan para pengguna dalam pengaksesan nya, dan juga bisa langsung digunakan dimanapun asalkan ada koneksi internet, Aplikasi sisten pakar ini memberikan berbagai pengetahuan, karena dalam aplikasi ini terdapat informasi mengenai penyebab dari penyakit tb paru serta mengenai bagaimana cara pencegahan dan penanganannya, sehingga dengan begitu pengguna dapat lebih cepat tanggap dalam menangani penyakit tb_paru ini.

Untuk pengembangan aplikasi selanjutnya dapat dilakukan pembuatan dalam versi android, supaya lebih memudahkan dalam mengakses, Pengembangan kedepannya sistem pakar diagnosa TB Paru ini mungkin bisa menggunakan metode lain selain menggunakan fuzzy logic ini.

\section{Referensi}

Wulandari, D. A., \& Prasetyo, A. (2018). Sistem Penunjang Keputusan Untuk Menentukan Status Gizi Balita Menggunakan Metode Fuzzy Tsukamoto. Jurnal Informatika, 22-33. 
Arumsari, M. D., \& Bujojo, P. P. (2010). TB Paru dan Gonitis TB Pada Anak. Journal of the Indonesian Medical Association.

Fanny , R. R., Hasibuan, N. A., \& Buulolo, E. (2017). Perancangan sistem pakar diagnosa penyakit asidosis tubulus renalis menggunakan metode certainty factor dengan penulusuran forward chaining. Media informatika budidarma, 13-16.

Huzumah, N., \& Arifn, T. (2018). Sistem Pemilihan Mesin Cuci Berdasarkan Kebutuhan Konsumen Menggunakan Fuzzy Tahani dan Promethee. Jurnal Informatika, 12-21.

Jogiyanto. (2005). Analisa \& Desain Sistem Informasi. Yogyakarta: Andi.

Kusrini. (2006). Sistem Pakar Teori dan Aplikasi. Yogyakarta: Andi Offset.

Laksono, A. D., Astuti, W. D., Waty, E., \& Atto'illah , A. (2012). Kajian Standar Pelayanan Minimal Penyakit Tuberkulosis Terkait Indikator Millenium Development Goals. Buletin Penelitian Sistem Kesehatan, 259-270.

Nasution, H. (2012). Implementasi Logika Fuzzy pada Sistem Kecerdasan Buatan. Jurnal ELKHA, 4-8.

Orhan, E., Temurtas, F., \& Tanrıkulu, A. Ç. (2010). Tuberculosis Disease Diagnosis Using Artificial Neural Networks. Journal of Medical Systems, 299-302.

Perwira, R. I., \& Aziz, A. (2014). Sistem Pakar Untuk Mendiagnosa Penyakit Infeksi TBC Paru. TELEMATIKA, 6374.

Rosa A. S, M. S. (2014). Rekayasa Perangkat Lunak: Terstruktur dan Berorientasi Objek. Bandung: Bandung Informatika.

Saputra, R. A. (2014). Penerapan Algortima naïve bayes untuk prediksi penyakit Tuberculosis (TB). Swabumi, 18-19.

Sari, B. N. (2015). Identifikasi Independensi Variabel Pengobatan Penyakit
Tuberkulosis Di Negara Asean Berdasarkan Struktur Dynamic Bayesian Network. Seminar Nasional Teknologi Informasi dan Multimedia (hal. 49-54). Yogyakarta: STMIK AMIKOM Yogyakarta.

Sulistyowati, I. (2011). Implementasi Sistem Pakar Berbasis Web Untuk Mendiagnosis Penyakit Dalam Pada Manusia. Seminar Nasional Teknologi Informasi \& Komunikasi Terapan 2011 (hal. -). Semarang: Universitas Dian Nuswantoro.

Suyanto. (2014). Artificial Intelligence. Bandung: Bandung Informatika.

Yazdi, P. M. (2014). Pemograman Matlab Pada Sistem Pakar Fuzzy. Yogyakarta: Deepublish.

Yuhefizar, d. (2006). Cara Mudah Membangun Website Interaktif Menggunakan Content Management Sistem Joomla. Jakarta: PT.Elex Media Komputindo. 